Annales Geophysicae (2001) 19: 837-843 C European Geophysical Society 2001

\title{
An improvement of wind velocity estimation from radar Doppler spectra in the upper mesosphere
}

\author{
S. Takeda ${ }^{1}{ }^{*}$, T. Nakamura ${ }^{1}$, and T. Tsuda ${ }^{1}$ \\ ${ }^{1}$ Radio Science Center for Space and Atmosphere, Kyoto University, Uji, Kyoto 611-0011, Japan \\ *Now at NTT DoCoMo, Inc.
}

Received: 23 October 2000 - Revised: 4 April 2001 - Accepted: 26 April 2001

\begin{abstract}
We have developed a new parameter estimation method for Doppler wind spectra in the mesosphere observed with an MST radar such as the MU radar in the DBS (Doppler Beam Swinging) mode. Off-line incoherent integration of the Doppler spectra is carried out with a new algorithm excluding contamination by strong meteor echoes. At the same time, initial values on a least square fitting of the Gaussian function are derived using a larger number of integration of the spectra for a longer time and for multiple heights. As a result, a significant improvement has been achieved with the probability of a successful fitting and parameter estimation above $80 \mathrm{~km}$. The top height for the wind estimation has been improved to around $95 \mathrm{~km}$. A comparison between the MU radar and the High Resolution Doppler Imager (HRDI) on the UARS satellite is shown and the capability of the new method for a validation of a future satellite mission is suggested.
\end{abstract}

Key words. Meteorology and atmospheric dynamics (middle atmosphere dynamics) - Radio science (remote sensing; signal processing

\section{Introduction}

The atmospheric structure in the mesosphere and lower thermosphere (MLT) region is observed with various instruments, such as MF radars, meteor radars, MST radars, imagers, lidars, etc. The MU radar is one of the MST radars, which was constructed at Shigaraki $\left(34^{\circ} 51^{\prime} \mathrm{N}, 136^{\circ} 06^{\prime} \mathrm{E}\right)$, Shiga prefecture, Japan in 1984 . Using the data obtained with the MU radar, the characteristics of gravity waves in the mesosphere have been eagerly studied (e.g. Yamamoto et al., 1987; Muraoka et al., 1987; Tsuda et al., 1989; Nakamura et al., 1993a, b), and comparisons with other radars, such as the Kyoto meteor radar (Tsuda et al., 1985), Adelaide MF $\operatorname{radar}\left(35^{\circ} \mathrm{S}, 138^{\circ} \mathrm{E}\right)$ (Nakamura et al., 1993), etc. have been

Correspondence to: T. Nakamura

(nakamura@kurasc.kyoto-u.ac.jp) carried out. In addition to such ground-based measurements, observations from satellites have been carried out recently, which have significantly contributed to research on global atmospheric dynamics. At the beginning of a satellite observation, validation of the measurement by comparison of the results with those obtained by ground-based instruments is very important.

The High Resolution Doppler Imager (HRDI) onboard the Upper-Atmosphere Research Satellite (UARS) is one of the instruments observing the wind field in the MLT region. Validation of wind velocity measurements by HRDI has been carried out by comparison with observations from MF radars (e.g. Burrage et al., 1993) and meteor radars (Hasebe et al., 1997), etc. Hasebe et al. (1997) compared wind velocities measured with HRDI, the Jakarta $\left(6.9^{\circ} \mathrm{S}, 107.6^{\circ} \mathrm{E}\right)$ meteor radar, and the meteor observation mode of the MU radar. Good agreement was shown except for the eastward component at around the $88 \mathrm{~km}$ altitude. It is important to determine whether or not the disagreement is due to an error (bias or offset of wind measurement) of HRDI or the meteor wind. Comparisons of wind measurements with another technique is, therefore, very helpful. In this sense, a MST radar observation with a sharp pencil beam and a high wind measurement accuracy is useful for validating the wind velocities measured with the satellite if the height range overlaps that of the satellite measurements. In past observations, the MU radar frequently could not measure the wind velocity above $85 \mathrm{~km}$ due to weak turbulence echoes, and, therefore, comparison with HRDI was not successful. In this study, in order to extend the height range of a successful parameter estimation, we improve the parameter estimation method, and compare the wind velocity measurements with HRDI and the MU radar turbulence observation mode by means of the new parameter estimation method.

\section{The MU radar mesosphere observation}

Routine observation with the MU radar of the middle and lower atmosphere for 4-5 successive days in a month has 
Table 1. Observational parameters of the mesosphere mode

\begin{tabular}{ll} 
IPP (Inter Pulse Period) & $730 \mu \mathrm{s}$ \\
Pulse Width & $4 \mu \mathrm{s}$ \\
Sample Interval & $2 \mu \mathrm{s}$ \\
Pulse Compression & 8 -element complementary \\
Sample Range & $59.9-89.3 \mathrm{~km}$ \\
Number of Coherent Integration & 20 times \\
Number of Incoherent Integration & 6 times \\
Number of FFT points & 128 \\
Number of Beam Directions & 5 \\
Number of Heights & 128 \\
\hline
\end{tabular}

been carried out for over 15 years. Turbulence scatter echoes are measured by means of the 5-beam Doppler Beam Swinging (DBS) method with a zenith angle of 10 degrees for oblique beams. One minute observations in the troposphere mode (observing $2-19 \mathrm{~km}$ ), the stratosphere mode $(5-25 \mathrm{~km})$, and the mesosphere mode $(60-98 \mathrm{~km})$ are alternately performed, resulting in a three minute interval for each height region. The parameters are obtained in real time during the observational period. After the observation, the Doppler spectra and estimated spectral parameters are stored in a mass storage system called the Data Archive System (DAS) at the Radio Science Center for Space and Atmosphere (RASC) at Kyoto University.

The observational parameters in the mesosphere are shown in Table 1. The time and height resolutions are 3 minutes and $600 \mathrm{~m}$ (sampled every $300 \mathrm{~m}$ ), respectively. In the mesosphere, the radar echo is due to the electron density fluctuation caused by turbulence with a scale of half of the radar wavelength (i.e. about $3 \mathrm{~m}$ ), and the radar echo is not strong enough at the higher altitude. At a higher altitude the electron density is larger, whereas the intensity of the turbulence with such a scale is not strong. Therefore, the echo was relatively strong in the height range of $70-80 \mathrm{~km}$, and the spectral parameters around 70-80 km could be more successfully estimated (Kubo et al., 1997). Unusual strong echoes were sometimes observed above the height range of $85 \mathrm{~km}$, where the turbulence with a scale of $3 \mathrm{~m}$ is not expected to be strong enough. In most cases, however, parameters at such an altitude were rarely estimated because of the weak returned signal. For example, in 1997, successful estimation was primarily possible in the height range of about $68-83 \mathrm{~km}$, out of the sampling height range of $59.9-98.3 \mathrm{~km}$. Consequently, time series analysis of 3-10 minute intervals has been carried out in a limited height range (e.g. Muraoka, 1994). On the other hand, wind velocity data should be averaged for 1-2 hours in order to obtain vertical profiles of the wind velocities (Tsuda et al., 1990). In this paper, we report analysis of the Doppler spectra by taking statistics and correlations in the time and height domains in order to estimate wind parameters more effectively than by averaging the data in a wider height range. At the time when the MU radar was constructed, this was impossible because of the limited processing speed and memory capacity of the computer. Recent advanced computer capa-

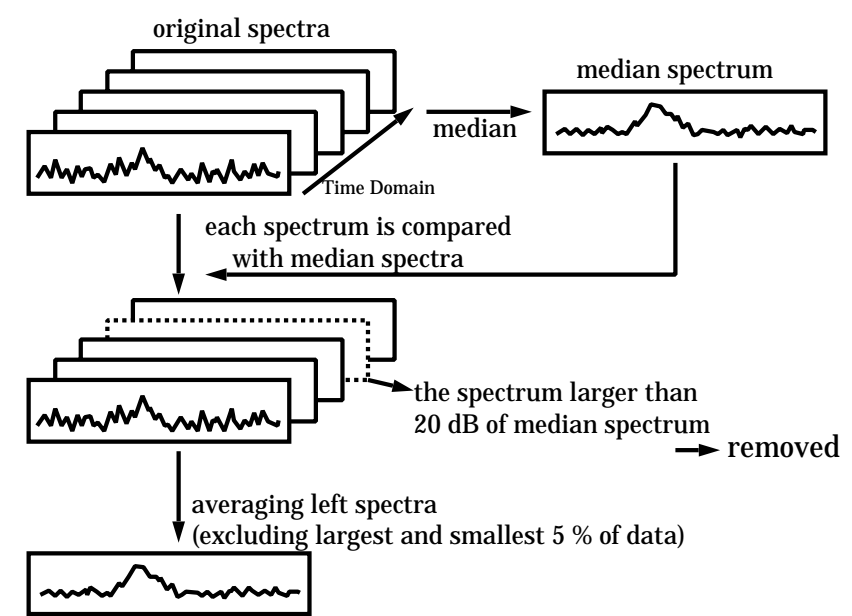

Fig. 1. The method of incoherent integration excluding contamination by meteor echoes.

bility enables more powerful data processing. Thus, Doppler spectra of multiple time and height records can be stored in the memory, and a more complicated algorithm with a statistical process can be applied, as described in Sect. 3. It is, however, noteworthy that Doppler spectra recorded in DAS have already been incoherently integrated for 1 minute (or 6 times).

\section{Improvement of parameter estimation}

The current means of parameter estimation of a Doppler spectrum for a mesospheric observation with the MU radar is the application of a least square fitting of a Gaussian function to the Doppler spectrum for each spectrum independently collected at each beam and height. The scattered radio signal is described by a Gaussian function with regards to the Doppler frequency, $f$, as follows,

$$
S(f)=\frac{P}{\sqrt{2 \pi \sigma}} \exp \left[-\frac{\left(f-f_{d}\right)^{2}}{2 \sigma^{2}}\right]+P_{N}
$$

where $P, f_{d}$ and $\sigma$ are the echo power, mean Doppler shift and spectral width, respectively, and $P_{N}$ is the noise level. This function is used for a least square fitting of the spectrum of the received signal in such a way that the squared sum of the error residual, $\epsilon^{2}$, becomes minimum. Therefore,

$$
\epsilon^{2}=\sum_{i=1}^{N}\left[y_{i}-S\left(f_{i} ; P, f_{d}, \sigma\right)\right]^{2}
$$

where $N$ and $y_{i}$ are the number of frequency points in the spectrum and the observed spectral density at frequency $f_{i}$, respectively. For an MU radar mesospheric observation, the fitting is executed in real time during the observation period. In other words, the fitting for all 5 beams and 128 heights is executed within one minute after the data is collected. Hereafter, this fitting is called the 'on-line fitting'. 

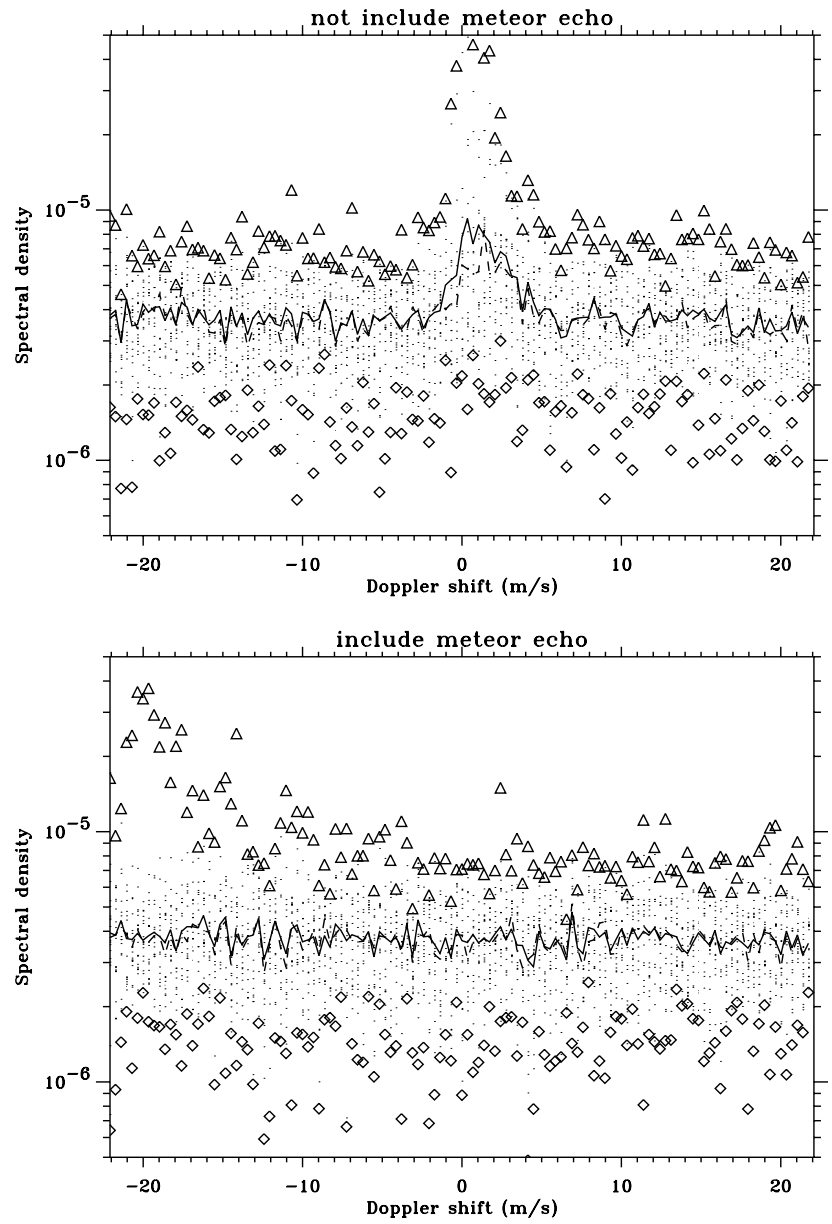

Fig. 2. Observed Doppler spectra with pure turbulence echoes (upper panel) and including meteor echoes (lower panel). Each dot is the spectral density measured on a one minute observation. In total, 20 spectra are plotted in the figure. Triangles and squares show the $5 \%$ (1 of 20 spectra) largest and smallest spectral density points. The solid and dashed lines show the spectra calculated with the improved integration and the median, respectively.

For a better estimation of spectral parameters, we took a few approaches. First, the Doppler spectra were integrated for a longer period than one minute. This operation, called "incoherent integration", improves the detectability $D$, which is defined as,

$D=\frac{P}{\sigma_{N}}$

where $\sigma_{N}$ is the standard deviation of noise fluctuation. Incoherent integration reduces the fluctuations inversely proportional to the square root of the number of integrations. Accordingly, after incoherent integration for $k$ times the detectability improves by $10 \log \sqrt{k} \mathrm{~dB}$ if the variation in the Doppler shift is small during the integration (e.g. Yamamoto et al., 1988). Therefore, a larger number of incoherent integration enables the detection of weaker signals. At the same time, the longer period of incoherent integration makes the time resolution worse. However, in this study, we first tried

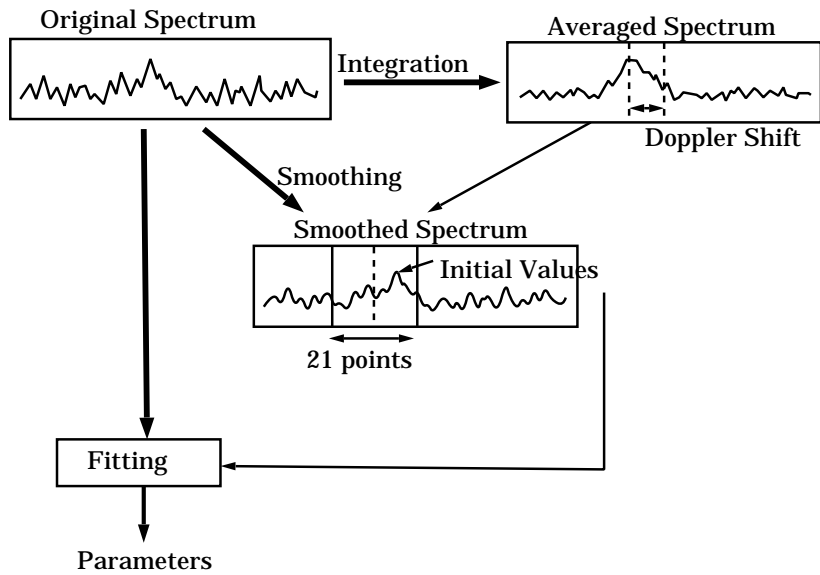

Fig. 3. Flowchart for deciding the initial value of fitting.

to improve the height range of successful wind estimation by a 1-2 hours time resolution, which corresponds to a period of averaging normally necessary to obtain a reasonably good wind profile by "on-line fitting".

The second improvement is the process of incoherent integration. Above the altitude of $80 \mathrm{~km}$, the echo scattered from the strong electron density caused by meteors (hereafter called 'meteor echo') is frequently received (Nakamura et al., 1997), which causes erroneous parameter estimation. It is necessary to integrate the Doppler spectra excluding the spectra with meteor echoes because the probability of including a meteor signal which prevents exact parameter estimation increases with a longer integration time. Detection of meteor echoes could be simple in a time series of received signals, as has been well established with the meteor radar technique. However, in the case of turbulent echo observation with the MU radar, Doppler spectra with one minute integration are stored, and the detection of meteors in the Doppler spectra is not easy. Hence, we need a more statistical technique to detect and remove contamination by meteor echoes. In the early stage of this study, contamination by meteor echoes was removed by taking a median of the Doppler spectra in the time domain. However, the median may remove strong turbulence echoes as well. Therefore, we applied a modification to the median, as will be described later.

The third improvement is the proper derivation of the initial values on a Gaussian fitting of th Doppler spectra by using a longer time and height averaging of spectra, which is similar to the method of parameter estimation of stratospheric data with the MU radar introduced by Sato (1997).

Figure 1 illustrates the data flow for the improved incoherent integration applied in this study. First, spectra are collected for a certain integration time, and the median spectral density value is calculated at each frequency point, and then a median spectrum is obtained, which becomes a reference for detecting a spectrum including a meteor trail echo. Second, Doppler spectra including a frequency component of $20 \mathrm{~dB}$ larger than the reference spectrum at the corresponding fre- 

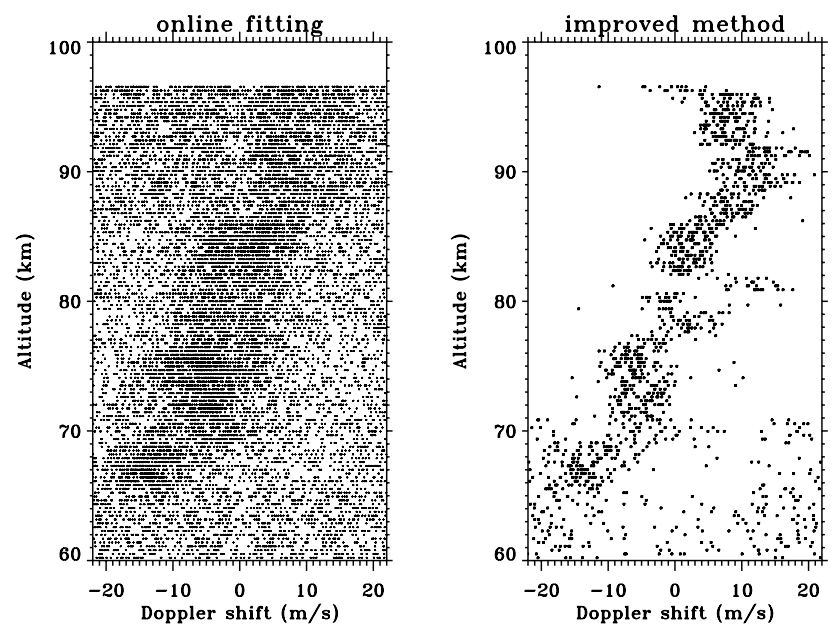

Fig. 4. Radial wind profile with the eastward beam on 16 July 1997. Left : On-line fitting. Right : Improved method (time resolution, 30 minutes).

quency are removed, which are regarded as spectra affected by meteors. There is still a possibility that spectra with meteor echo are included, which are stronger than the reference median spectrum, but not as large as $20 \mathrm{~dB}$. Therefore, another approach is taken in order to remove contamination by the Doppler spectra, including more faint meteor echoes. At each frequency point, $5 \%$ of the largest and smallest spectral densities are removed and the rest are integrated. This threshold of 5\% is chosen by assuming that such meteor echo contamination is less than one event per hour with a single height and beam. Figure 2 shows examples of Doppler spectra with and without a meteor echo. These are examples that indicate that the averaging adopted here gives a better spectrum than the simple median value. However, it might be better to adjust the threshold by closer investigation of the meteor echo occurrence.

Figure 3 illustrates the process for deriving the initial values. First, the spectra are integrated for the time period of a desired time resolution (this integrated spectrum is hereafter called the "original spectrum"). The original spectra are further integrated for 11 (i.e. \pm 5 ) points in time and for 3 (i.e. \pm 1 ) points in height, producing an "averaged spectrum". At the same time, the original spectrum is smoothed in the frequency domain by means of a weighting function of a raised cosine with a width of 5 frequency points (1.7 $\mathrm{m} / \mathrm{s}$ in Doppler velocity) in HWFW, and a "smoothed spectrum" is obtained. Then, spectral parameters are estimated from the averaged spectrum by the current fitting method. The estimated Doppler shift is used as a reference for choosing a maximum spectral density in the smoothed spectrum in the frequency range $\pm 10( \pm 3.4 \mathrm{~m} / \mathrm{s})$ points of reference. The corresponding frequency for the peak of the smoothed spectrum is used as an initial value of the Doppler shift in the final Gaussian fitting. Here, it is notable that parameter estimation of echo power and Doppler shift is improved by this method, but the spectral width estimated here could be

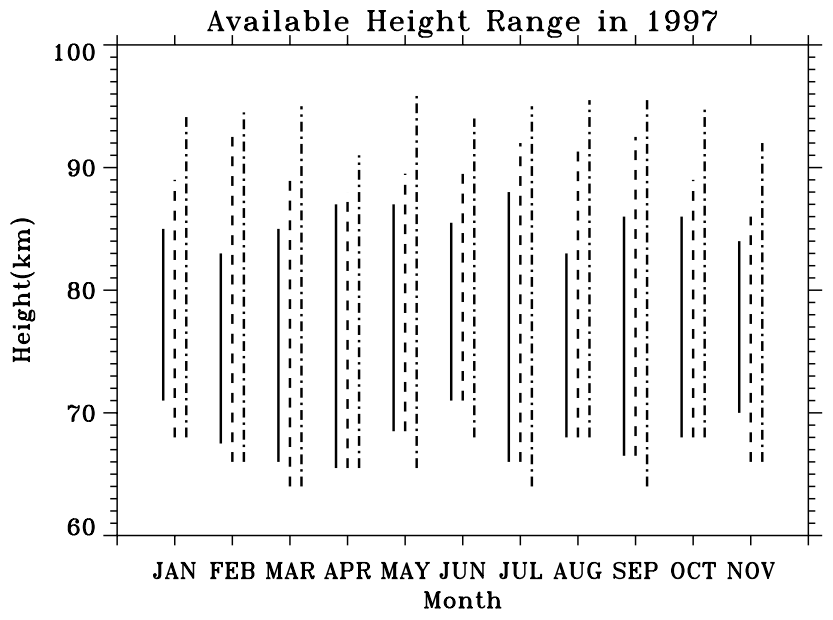

Fig. 5. The height range of parameter estimation in each month in 1997. Solid, dashed and chained lines correspond to the heights of successful estimation with on-line fitting ( 3 min resolution), the new method ( 3 min resolution), and the new method (30 min resolution), respectively.

biased and larger than that caused by turbulence due to the influence of gravity wave oscillations within the incoherent integration time.

We compared the height range of successful parameter estimation between on-line fitting and the improved method. Two integration times with the improved method were chosen, which were 3 minutes (equal to the on-line fitting) and 30 minutes. All observational data for the mesosphere in 1997 (57 days) were analyzed using this improved method in order to investigate the efficiency of the improvements.

First, the distribution of wind velocities on a selected day (16 July 1997) is plotted in Fig. 4. Each point shows the radial wind velocity of the eastward beam at each height and at each observation time. Fluctuations in the vertical wind and the eastward wind appear as the horizontal dispersion of the data points. However, wide dispersions, such as, those shown at heights above $87 \mathrm{~km}$ in the left figure, are thought to represent erroneous parameter estimation. Then the height range of correct parameter estimation can be estimated from the width of dispersion. The wind velocity measurement by on-line fitting (left figure) was successful at the altitude of $67-86 \mathrm{~km}$. In contrast, the improved method (right figure) produces good results at the altitude of $65-95 \mathrm{~km}$ in this case. Turbulence with a scale of about $3 \mathrm{~m}$ ought to be very weak in a higher height region such as $85-95 \mathrm{~km}$. However, electron density and its vertical gradient significantly increase with height. As a result, turbulence echoes are enhanced by strong electron density gradients and could be received even at such high altitudes. Such an enhancement has been reported by Kubo et al. (2001), who showed that the volume reflectivity exhibits a second maximum at $85-90 \mathrm{~km}$.

Such comparisons have been executed for wind velocities on each day in 1997. The height ranges of successful wind determination on each day are averaged monthly and plot- 
Table 2. Difference in resolution between the MU radar and HRDI

\begin{tabular}{lll}
\hline & MU radar & HRDI \\
\hline time resolution & $15 \mathrm{~min}$ & $8 \mathrm{~min}$ \\
range resolution & $600 \mathrm{~m}$ & $4000 \mathrm{~m}$ \\
horizontal scale & $20-35 \mathrm{~km}$ & $100-200 \mathrm{~km}$ \\
\hline
\end{tabular}

Table 3. List of days for data comparison

\begin{tabular}{lrc}
\hline Day & UT (s) & Distance $(\mathrm{km})$ \\
\hline $15 / 12 / 1992$ & 6827 & 334.5 \\
$18 / 12 / 1992$ & 19257 & 316.8 \\
$12 / 01 / 1993$ & 1419 & 391.8 \\
$14 / 05 / 1993$ & 2559 & 171.1 \\
$02 / 12 / 1993$ & 15979 & 555.0 \\
$24 / 12 / 1993$ & 21071 & 84.3 \\
$15 / 02 / 1994$ & 17996 & 463.7 \\
$17 / 05 / 1994$ & 18353 & 967.7 \\
$19 / 05 / 1994$ & 18810 & 111.2 \\
$06 / 07 / 1994$ & 7510 & 280.5 \\
$20 / 09 / 1994$ & 15478 & 240.3 \\
$22 / 09 / 1994$ & 15987 & 569.8 \\
$18 / 10 / 1994$ & 10090 & 220.0 \\
$15 / 11 / 1994$ & 19642 & 525.8 \\
\hline
\end{tabular}

ted in Fig. 5. Remarkable improvements are recognized in all months. In particular, the top of the height ranges has become significantly higher. This is probably due to the exclusion of meteor echoes at a higher altitude. The yearly average height ranges with the on-line fitting (solid line), the improved method of a 3 minute resolution (dashed line), and the improved method of a 30 minute resolution (chained line) are about $68-85 \mathrm{~km}, 67-90 \mathrm{~km}$, and $66-94 \mathrm{~km}$, respectively. The yearly averaged height range with the improved method of a 3 minute resolution is about $6 \mathrm{~km}$ larger than that with the on-line fitting, which indicates the improvement in deriving the initial values since these two results involve the same time resolution. The yearly averaged height range with the improved method of a 30 minute resolution (chained line) is about $5 \mathrm{~km}$ larger than that in the case of 3 minutes, which indicates the effect of the longer integration time at a sacrifice of time resolution.

\section{Comparison of wind velocity with UARS/HRDI}

Because of improvement of the top of the height range of successful parameter estimation, it is easier and more meaningful to compare the wind profiles obtained with the MU radar turbulence echoes with other wind measurements in the MLT region.

The Upper-Atmosphere Research Satellite (UARS) is a satellite launched on 12 September 1991 that observes the atmospheric composition, temperature and wind velocity. There are two instruments for observing the wind profiles
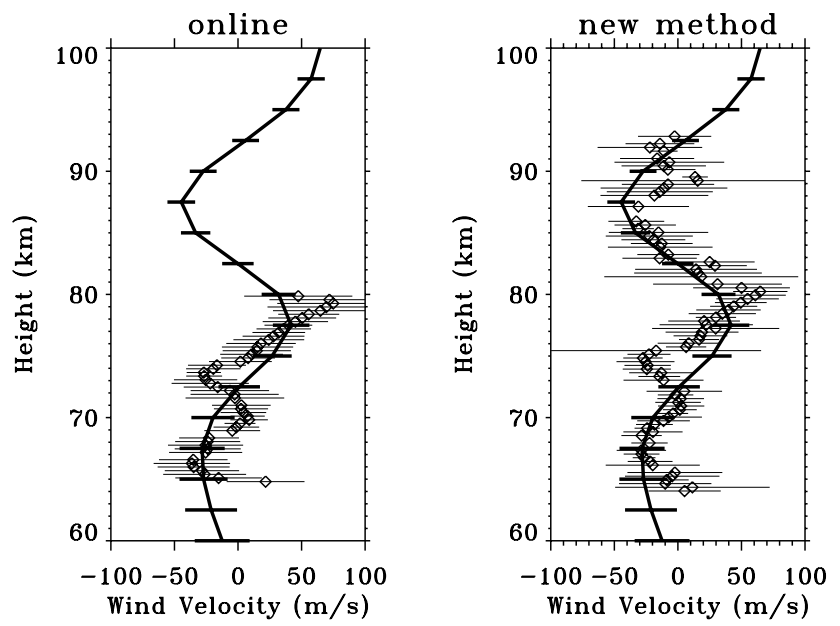

Fig. 6. Comparison of the meridional wind profiles between HRDI (thick line) and the MU Radar (squares) with 15 minute resolution data and the standard deviation (thin line) on 18 October 1994. The HRDI overpass over the MU radar occurred at 11:10 LT. The wind velocity for the MU radar in the left figure is that obtained by online fitting, and that in the right figure is that obtained by the new method with a time resolution of 15 minutes.

in the MLT region on UARS. One is the Wind Imaging Interferometer (WINDII), which observes wind velocity at the altitude of 80-300 km by measuring the emission lines of neutral and ionized atomic oxygen, the $\mathrm{OH}$ molecule, and the molecule-oxygen. The other is the High Resolution Doppler Imager (HRDI), which observes the wind velocity in the stratosphere, mesosphere, and lower thermosphere by measuring the Doppler shifts of spectral lines within the atmospheric band system of molecular oxygen during the day, and the emission lines of neutral and ionized atomic oxygen during the day and night (Burrage et al., 1997).

In this section, the wind velocity observed with the MU radar is compared with that of the HRDI. Table 2 shows the time, range and scale resolution of the MU radar and HRDI. The time resolution of the MU radar in the current analysis was 15 minutes, but the data are averaged for 1 hour around the HRDI's overpass. Examples of the wind profiles observed with HRDI and the MU radar are shown in Fig. 6. The error bars for the MU radar (thin lines) indicate standard deviations of wind velocities measured independently during 1 hour. This standard deviation is derived from standard deviations in the oblique beam in opposite azimuths. Therefore, the standard deviations of zonal and meridional winds include the standard deviation of vertical winds as well. In this figure, the wind profile for the MU radar fluctuates around the HRDI profile. It is considered that the MU radar detected the small vertical scale variations due to gravity waves, and HRDI smoothed them out due to a poorer height resolution.

Such comparisons can be executed when the HRDI observation is carried out near the MU radar site during the MU radar mesospheric observation. Here, the data which HRDI obtained within $1000 \mathrm{~km}$ of the MU radar are compared. So 

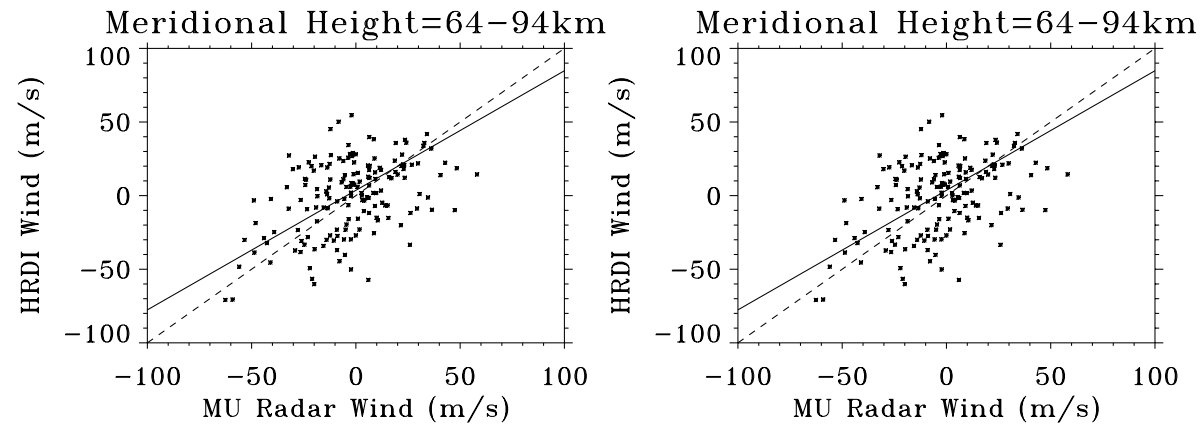

Fig. 7. Scatter diagram of the wind velocity observed with UARS/HRDI ( $y$ axis) and the MU radar ( $x$-axis). The solid line is the best fit line. The MU radar wind was estimated with a 15 minute resolution. far, 14 events have been compared, as shown in Table 3. The results of the comparison are plotted in Fig. 7 as a scatter diagram of wind velocities. The MU radar wind is averaged over $2500 \mathrm{~m}$ in height, which equals the data interval height of HRDI. Each standard deviation of the MU radar wind is derived from wind velocities within the time in each height range.

The best fit line is calculated by the least square method, using the inverse of the variance of observed wind velocities as the weight of each wind measurement. The fitting process is slightly different from the normal procedure since not only the $y$ value, but also the $x$ value includes an error. The error residual is shown as follows

$\epsilon^{2}=\sum_{i=0}^{N}\left[\frac{\left(y_{i}-f\left(x_{i}^{0}\right)\right)^{2}}{\sigma_{y i}^{2}}+\frac{\left(x_{i}-x_{i}^{0}\right)^{2}}{\sigma_{x i}^{2}}\right]$

where $\left(x_{i}, y_{i}\right)$ is the measured wind velocity with the MU radar and HRDI, $\left(\sigma_{x i}, \sigma_{y i}\right)$ is the standard deviation of it, and the fitting function is shown as $f(x)=a x+b$, using fitting parameters, $a$ and $b$. Here, $x_{i}^{0}$, which is the true value of the MU radar wind $x$, is estimated simultaneously when estimating the fitting parameters, $a$ and $b$.

The estimated parameters (and confidence intervals), $a$ $\left(\sigma_{a}\right)$ and $b\left(\sigma_{b}\right)$ for the meridional wind are $0.81( \pm 0.038)$ and $3.6( \pm 0.92)$, and those for the zonal wind are 1.32 $( \pm 0.037)$ and $6.7( \pm 1.1)$. The wind velocity with HRDI has been observed to be smaller than that with the MU radar in the meridional component and larger in the zonal component. Overestimation of the HRDI wind in the zonal component has been similarly found as a result of the validation of HRDI MLT winds with meteor radars (Hasebe et al., 1997). However, there is still some uncertainty regarding these results for a few reasons. First, the observational sample area for HRDI is not completely identical to that of the MU radar. Therefore, the wind velocities at two different locations are not always identical. This is especially true at these heights because gravity waves are always present. Second, all the samples shown here are not independent because winds at different heights in the same profile are treated as different samples. Correlations between the samples can cause a smaller standard deviation of $a$ than the real one. Nevertheless, it is important that through the improvement of wind velocity analysis introduced here, very useful comparisons between
MST data and those obtained with a satellite or other radars has become possible.

\section{Conclusion}

The parameter estimation on the MU radar mesospheric observation has been improved. The number of incoherent integration has increased. A natural meteor echo rejection process has been adopted. Better initial values on a Gaussian least-square fitting have been deduced. The improved parameter estimation was applied to the data obtained in 1997, and we found that the height range of successful parameter estimation has been significantly expanded, especially the upper boundary of the range, which has increased up to about $95 \mathrm{~km}$. This improvement has made the comparison of the wind profiles with other measurements much more useful. Using the improved method, the wind velocities measured with the MU radar were compared with UARS/HRDI winds. The wind velocities with the HRDI are smaller than those of the MU radar in the meridional component and larger in the zonal component, which is similar to the results obtained by Hasebe et al. (1997) on a comparison with a meteor radar. Although the number of samples for such a comparison of the MU radar and HRDI was small, the newly developed technique shown here will contribute significantly to future comparisons of the MU radar and other instruments, or the validation of a new satellite mission.

Acknowledgements. The MU radar belongs to and is operated by Radio Science Center of Space and Atmosphere, Kyoto University. The authors deeply appreciate Dr. Mark Burrage and the HRDI science team for providing the data for comparisons.

Topical Editor D. Murtagh thanks a referee for his help in evaluating this paper.

\section{References}

Burrage, M. D., Skinner, W. R., Marshall, A. R., Hays, P. B., Lieberman, R. S., Franke, S. J., Gell, D. A., Ortland, D. A., Morton, T. Y., Schmidlin, F. J., Vincent, R. A., and Wu, D. L., Comparison of HRDI wind measurements with radars and rocket observations, Geophys. Res. Lett., 20, 1259-1262, 1993. 
Burrage, M. D., Skinner, W. R., and Hay, P. B., Intercalibration of HRDI and WINDII wind measurements, Ann. Geophysicae, 15, 1089-1098, 1997.

Hasebe, F., Tsuda, T., Nakamura, T., and Burrage, M. D., Validation of HRDI MLT winds with meteor radars, Ann. Geophysicae, 15, 1142-1157, 1997.

Kubo, K., Sugiyama, T., Nakamura, T., and Fukao, S., Seasonal and interannual variability of mesospheric echoes observed with the middle and upper atmosphere radar during 1986-1985, Geophys. Res. Lett., 24, 1211-1214, 1997.

Kubo, K., Sugiyama, T., Nakamura, T., and Fukao, S., Evaluation of mesospheric VHF echoes observed with the MU radar, Radio Sci., 2001 (submitted).

Muraoka, Y., Kawahira, K., Sato, T., Tsuda, T., Fukao, S., and Kato, S., Characteristics of mesospheric internal gravity waves observed by the MU radar, J. Geophys. Res., 14, 1154-1157, 1987.

Muraoka, Y., Fukao, S., Tsuda, T., and Sugiyama, T., Saturation of frequency spectra for mesospheric wind velocity observed with the middle and upper atmosphere radar, J. Geophys. Res., 99, 19485-19497, 1994.

Nakamura, T., Tsuda, T., Fukao, S., Takahashi, H., Batista, P. P., Buriti, R. A., Tsutsumi, M., Ishii, M., Igarashi, K., Fukunishi, H., Yamada, Y., Nomura, A., Kawahara, T. D., Kobayashi, K., Nagasawa, C., Abo, M., and Talor, M. J., Studies of the MLT region using the MU radar and simultaneous observations with $\mathrm{OH}$ spectrometer and other optical instruments, Adv. Space Res., 19, 643-652, 1997.

Nakamura, T., Tsuda, T., Yamamoto, M., Fukao, S., and Kato, S., Characteristics of gravity waves in the mesosphere observed with the MU radar: 1. momentum flux, J. Geophys. Res., 98, 8899-
8910, 1993a.

Nakamura, T., Tsuda, T., Yamamoto, M., Fukao, S., and Kato, S., Characteristics of gravity waves in the mesosphere observed with the MU radar: 2. propagation direction, J. Geophys. Res., 98, 8911-8923, 1993b.

Nakamura, T., Tsuda, T., Fukao, S., Kato, S., and Vincent, R. A., Comparison of the mesospheric gravity waves observed with the MU radar $\left(35^{\circ} \mathrm{N}\right)$ and the Adelaide $\mathrm{MF}$ radar $\left(35^{\circ} \mathrm{S}\right)$, Geophys. Res. Lett., 20, 803-806, 1993c.

Sato, K., Low-frequency inertia-gravity waves in the stratosphere revealed by three-week continuous observation with MU radar, J. Geophys. Res., 24, 1739-1742, 1997.

Tsuda, T., Yamamoto, M., Sato, T., Kato, S., and Fukao, S., Comparison observations between the MU radar and the Kyoto meteor radar, Radio Sci., 20, 1241-1246, 1985.

Tsuda, T., Inoue, T., Fritts, D. C., VanZandt, T. E., Kato, S., Sato, T., and Fukao, S., MST radar observations of a saturated gravity wave spectrum, J. Atmos. Sci., 46, 2440-2447, 1989.

Tsuda, T., Kato, S., Yokoi, T., Inoue, T., Yamamoto, M., VanZandt, T. E., Fukao, S., and Sato, T., Gravity waves in the mesosphere observed with the middle and upper atmosphere radar, Radio Sci., 46, 2440-2447, 1990.

Yamamoto, M., Tsuda, T., Kato, S., Sato, T., and Fukao, S., A saturated inertia gravity wave in the mesosphere observed by the middle and upper atmosphere radar, J. Geophys. Res., 92, 11993 11999, 1987.

Yamamoto, M., Sato, T., May, P. T., Tsuda, T., Fukao, S., and Kato, S., Estimation error of spectral parameters of mesospherestratosphere-troposphere radars obtained by least squares fitting method and its lower bound, Radio Sci., 23, 1013-1021, 1988. 